harness type hospital (1 December, p 1513). In addition to the units mentioned in the article a geriatric unit built to the harness design opened here in North Tees Genera Hospital in March 1975. Since then many problems relating to the roof design have occurred, resulting in a great deal of inconvenience to patients and staff, and on one occasion necessitating largescale evacuation of patients from the unit.

We now find ourselves less than 10 years on in the position of having to reroof the whole building, despite the fact that the department's architect acknowledges that the roof design is unsatisfactory. North Tees Health District is having to bear the full cost of the replacement, and, although some help is being obtained through brokerage from the regional health authority, the cost of around $£ 350000$ will obviously curtail other capital developments in the district for years to come.

I feel that the bitter pill we have had to swallow may well be of interest to other districts taking "departmental designs" of the shelf.

Department of Elderly Care North Tees General Hospital, Stockton-on-Tees,

\section{Algorithm for modified alkaline diuresis in salicylate poisoning}

SIR,-As the authors of a recent review in the journal on eliminating poisons ${ }^{1}$ we were naturally interested to read the report by Dr I J Gordon and others (20 October, p 1039) on the use of modified alkaline diuresis in the treatment of salicylate poisoning. We agree with Prescott and others that alkali alone is at least as effective as the "cocktail" formerly advocated by the Edinburgh Regional Poisons Treatment Centre. ${ }^{2}$ Nevertheless, we are unimpressed with the regimen set out by Dr Gordon and his coauthors and believe no only that it may be ineffective but also that it may be hazardous for the following reasons.

Firstly, the authors state that the regimen failed in one of six cases.

Secondly, we are not told whether alkaline diuresis was in fact achieved ("Routine monitoring of urine $\mathrm{pH}$ was found to be unnecessary.")

Thirdly, no estimate of salicylate excretion was made by the authors. Efficacy is therefore difficult to judge, as part of the decrease in plasma salicylate concentration may have been due to the intravenous infusion of two litres of fluid.

Fourthly, two of the six patients developed pronounced hypokalaemia $(2.5$ and $2.4 \mathrm{mmol}$ $(\mathrm{mEq}) / 1$ respectively)

Fifthly, estimation of plasma $\mathrm{pH}$ is not recommended in the authors' algorithm as part of the initial assessment. This is a serious omission as adult patients poisoned with salicylates commonly develop a metabolic acidosis. A patient with a plasma salicylate concentration of $500 \mathrm{mg} / \mathrm{l}$ or more and an associated metabolic acidosis has an entirely different prognosis from one with normal acid base balance, and there should be no delay in treatment.

Finally, in our opinion a recommendation to repeat the measurement of salicylate concentration after four hours is incorrect, even if the initial figure lies below $500 \mathrm{mg} / \mathrm{l}$. If this advice is followed the result is unlikely to be available much before five hours, by which time the salicylate concentration may have risen substantially without a noticeable change in symptoms. We would therefore recommend repeating the measurement of salicylate concentration after two hours.

Forced alkaline diuresis is a metabolically invasive procedure and requires close super- vision. The regimen needs to be adjusted to the individual needs of each patient using the principles outlined in our paper. Only then will alkaline diuresis, forced or otherwise, be achieved and be both effective and safe.

\section{J A VAle} BRENDAN M BUCKLEY

West Midlands Poisons Unit, Birmingham B18 7QH

\section{Guy's Hospital,
London SE1 9RT}

T J MEREDITH

1 Vale A, Meredith T, Buckley B. ABC of poisoning: eliminating poisons. $\mathrm{Br}$ Med $尹$ 1984;289:366-9.

Prescott LF, Balali-Mood M, Critchely JAJH,
Johnstone AF, Proudfoot AT. Diuresis or urinary alkalinisation for salicylate poisoning. $\mathrm{Br}$ Med 1982;285:1383-6.

\section{${ }_{*}^{*}$ Dr Gordon replies below.-ED, BMf.}

SIR,-Several of the criticisms raised by Dr Vale and his colleagues are answered by close scrutiny of our paper.

Firstly, the regimen succeeded in five out of six patients. The sixth patient had severe poisoning (salicylate level $800 \mathrm{mg} / \mathrm{l}$ on admission) and in view of the poor result we did not recommend future use of the modified regimen for this degree of poisoning.

On the second and third points, the plasma salicylate concentrations may be falsely reduced after infusion of large volumes of fluid due to a dilutional effect. Since the amount of fluid in our regimen is considerably less than in conventional forced alkaline diuresis, we believe that the plasma salicylate concentration is a good guide to efficacy. For the five patients successfully treated, the mean salicylate concentration fell from $584 \mathrm{mg} / 1$ to $413 \mathrm{mg} / \mathrm{l}$ at four hours. This is far in excess of that expected because of a dilutional effect from two litres of fluid. In view of these results we decided that it was unnecessary routinely to monitor urine $\mathrm{pH}$ so long as a satisfactory fall in salicylate level occurred at four hours.

Fourthly, hypokalaemia developed in the patient whom we subsequently considered unsuitable for the regimen and in one other patient in whom serum potassium returned to normal four hours after the infusion was stopped.

Fifthly, we agree that there should be no delay in treating patients with salicylate concentration of more than $500 \mathrm{mg} / 1$ together with metabolic acidosis, and our paper does not imply anything to the contrary.

Finally, Dr Vale and others suggest two hours as the optimum time to recheck the salicylate concentration after lavage; they have previously suggested "several hours," while 30 minutes has also been advocated. ${ }^{2}$ Presumably no specific time period has achieved widespread acceptance.

Salicylate poisoning is common, and many patients are treated on general medical wards in district general hospitals, where monitoring of a conventional forced diuresis may be inadequate. This regimen was devised for use in such circumstances and for when there is no immediate access to intensive care facilities. Dr Vale and his colleagues think that this algorithm may be hazardous and ineffective. In our opinion it is considerably less hazardous than conventional forced alkaline diuresis used on an open ward, while its efficacy in treating moderate poisoning has been clearly shown in our paper.

Broadgreen Hospital,
Liverpool L14 3LB

I J GORDON

1 Meredith TJ, Vale JA. Salicylate poisoning. In: Vale JA, Meredith TJ, eds. Poisoning diagnosis an treatment. London: Update Books, 1981:97-103.

2 Lawson AAH. Acute salicylate poisoning. In: Jones ES, ed. Essential intensive care. Lancaster MTP Press, 1978:385-92.
Clinical algorithms: generalised pruritus

SIR,-I am not competent to judge the dermatological aspects of Dr R H Champion's article (22 September, 1984), which seems very comprehensive. I do, however, take exception to the item which says, "Reluctantly, and by exclusion, consider: psychogenic pruritus (only with psychiatric abnormalities)."

I suspect that psychogenic pruritus is important enough to warrant a less inconspicuous place in the algorithmic schema. I also find it disturbing that a clinician should advise us to diagnose anything "reluctantly and by exclusion." Good medical practice surely demands that we approach the patient's condition without preconceived bias and that we diagnose disorders on their positive features, rather than as the end product of excluding everything else. From a psychiatrist's viewpoint $\mathrm{Dr}$ Champion's proposal is an invitation to overlook any but the grossest psychopathology and an injunction to consider the possibility of psychiatric illness only after all the alternatives have been thoroughly discredited. Surely everyday clinical practice has long since rejected such an approach.

Department of Psychiatry,

Alistair Munro Halifax, Nova Scotia B3H 3G2

${ }^{*} *$ Dr Champion replies below.-ED, $B M F$.

SIR,-I think that Professor Munro and I are trying to tell the same story. My apologies if the framework of an algorithm did not make this abundantly clear.

The message I wished to convey and indeed now wish to uphold is that psychogenic pruritus is a dangerous diagnosis until other causes have been excluded and that even then the diagnosis should be substantiated on positive psychiatric grounds and not just because no other cause has emerged. Perhaps my views are coloured by having personally observed patients with Hodgkin's disease and with biliary cirrhosis whose pruritus had been labelled psychogenic and, indeed, who had achieved some symptomatic relief from an excellent psychiatrist. So many skin disorders have multiple causes, why not itching ? Even a solitary insect bite is more itchy when one is tired.

Department of Dermatology,

R H CHAMPION Addenbrooke's Hospital, Cambridge CB2 $2 \mathrm{QQ}$

\section{Value of follow up in testicular cancer}

SIR,-We would like to support the view of $\mathrm{Dr}$ Matthew Ellis and others (24 November, $p$ 1423) that intensive follow up, especially radiological, is unnecessary in many patients with testicular cancer.

Most patients with seminoma do not have disease which has advanced beyond the paraaortic area. Provided there is no palpable abdominal mass and the intravenous urogram used for radiotherapy planning is normal then para-aortic disease, if present, will almost invariably fall within a standard radiotherapy field. Computed tomography can therefore be reserved for those patients with an abnormal intravenous urogram or other features that raise clinical suspicion. Only 10 out of 239 patients in this group treated at the Christie Hospital from 1970 to 1978 relapsed, of whom 